\title{
Hot topic: Enhancing omega-3 fatty acids in milk fat of dairy cows by using stearidonic acid-enriched soybean oil from genetically modified soybeans
}

\author{
G. Bernal-Santos, ${ }^{* 1,2}$ A. M. O’Donnell, ${ }^{* 1}$ J. L. Vicini, $†$ G. F. Hartnell, $†$ and D. E. Bauman ${ }^{* 3}$ \\ *Department of Animal Science, Cornell University, Ithaca, NY 14853 \\ †Monsanto Co., St. Louis, MO 63167
}

\section{ABSTRACT}

Very long chain n-3 fatty acids such as eicosapentaenoic acid (EPA; 20:5n-3) are important in human cardiac health and the prevention of chronic diseases, but food sources are limited. Stearidonic acid (SDA; $18: 4 n-3)$ is an n-3 fatty acid that humans are able to convert to EPA. In utilizing SDA-enhanced soybean oil (SBO) derived from genetically modified soybeans, our objectives were to examine the potential to increase the n-3 fatty acid content of milk fat and to determine the efficiency of SDA uptake from the digestive tract and transfer to milk fat. Three multiparous, rumenfistulated Holstein cows were assigned randomly in a 3 $\times 3$ Latin square design to the following treatments: 1 ) control (no oil infusion); 2) abomasal infusion of SDAenhanced SBO (SDA-abo); and 3) ruminal infusion of SDA-enhanced SBO (SDA-rum). The SDA-enhanced SBO contained $27.1 \%$ SDA, $10.4 \%$ - - -linolenic acid, and $7.2 \% \gamma$-linolenic acid. Oil infusions provided $57 \mathrm{~g} / \mathrm{d}$ of SDA with equal amounts of oil infused into either the rumen or abomasum at 6 -h intervals over a 7 -d infusion period. Cow numbers were limited and no treatment differences were detected for DMI or milk production $(22.9 \pm 0.5 \mathrm{~kg} / \mathrm{d}$ and $32.3 \pm 0.9 \mathrm{~kg} / \mathrm{d}$, respectively; least squares means $\pm \mathrm{SE}$ ), milk protein percentage and yield $(3.24 \pm 0.04 \%$ and $1.03 \pm 0.02 \mathrm{~kg} / \mathrm{d})$, or lactose percentage and yield $(4.88 \pm 0.05 \%$ and $1.55 \pm 0.05$ $\mathrm{kg} / \mathrm{d})$. Treatment also had no effect on milk fat yield $(1.36 \pm 0.03 \mathrm{~kg} / \mathrm{d})$, but milk fat percentage was lower for the SDA-rum treatment $(4.04 \pm 0.04 \%$ vs. $4.30 \pm$ $0.04 \%$ for control and $4.41 \pm 0.05 \%$ for SDA-abo). The SDA-abo treatment increased n-3 fatty acids to $3.9 \%$ of total milk fatty acids, a value more than 5 -fold greater than that for the control. Expressed as a percentage of total milk fatty acids, values (least squares means \pm

\footnotetext{
Received September 9, 2009.

Accepted November 6, 2009.

${ }^{1}$ The first two authors contributed equally to this study.

${ }^{2}$ Present address: Universidad Autónoma de Querétaro, Facultad de Ciencias Naturales, Medicina Veterinaria y Zootecnia, Querétaro, Qro. CP 76000, México.

${ }^{3}$ Corresponding author: deb6@cornell.edu
}

$\mathrm{SE})$ for the SDA-abo treatment were $1.55 \pm 0.03 \%$ for $\alpha$-linolenic acid (18:3n-3), $1.86 \pm 0.02$ for SDA, 0.23 $\pm<0.01$ for eicosatetraenoic acid (20:4n-3), and 0.18 \pm 0.01 for EPA. Transfer efficiency of SDA to milk fat represented $39.3 \%$ (range $=36.8$ to $41.9 \%$ ) of the abomasally infused SDA and $47.3 \%$ (range $=45.0$ to $49.6 \%$ ) when the $\mathrm{n}-3$ fatty acids downstream from SDA were included. In contrast, transfer of ruminally infused SDA to milk fat averaged only $1.7 \%$ (range $=1.3$ to $2.1 \%$ ), indicating extensive rumen biohydrogenation. Overall, results demonstrate the potential to use SDAenhanced SBO from genetically modified soybeans combined with proper ruminal protection to achieve impressive increases in the milk fat content of SDA and other n-3 fatty acids that are beneficial for human health.

Key words: stearidonic acid, eicosapentaenoic acid, omega-3 fatty acid, human health

Very long chain (VLC) n-3 polyunsaturated fatty acids (PUFA) are essential for growth and development and are beneficial in the maintenance of human health and the prevention of chronic diseases including cardiovascular disease, inflammatory diseases, and neurological disorders (Gebauer et al., 2006; Wang et al., 2006; Yashodhara et al., 2009). The main dietary sources of eicosapentaenoic acid (EPA; 20:5n-3) and docosahexaenoic acid (DHA; 22:6n-3) are marine algae, fish, and fish oils. Nevertheless, the estimated intakes of VLC n-3 PUFA are very low despite the dietary guidelines, and most of the US population consumes substantially less than the recommended levels (Ursin, 2003; Gebauer et al., 2006). Hence, there is a need to develop alternative food sources to increase consumption of VLC n-3 PUFA (Whelan and Rust, 2006).

Milk fat levels of n-3 fatty acids are typically very low, less than $0.5 \%$ of total fatty acids, and this is mainly $\alpha$-linolenic acid (ALA; 18:3n-3; Jensen, 2002). $\alpha$-Linolenic acid is an essential n-3 fatty acid for some development processes; however, conversion of ALA to VLC n-3 PUFA is necessary for other physiological functions and essential for optimum health and the prevention of chronic diseases (Wang et al., 2006; Lavie 
$\alpha$-Linolenic acid (ALA)

$18: 3 n-3$

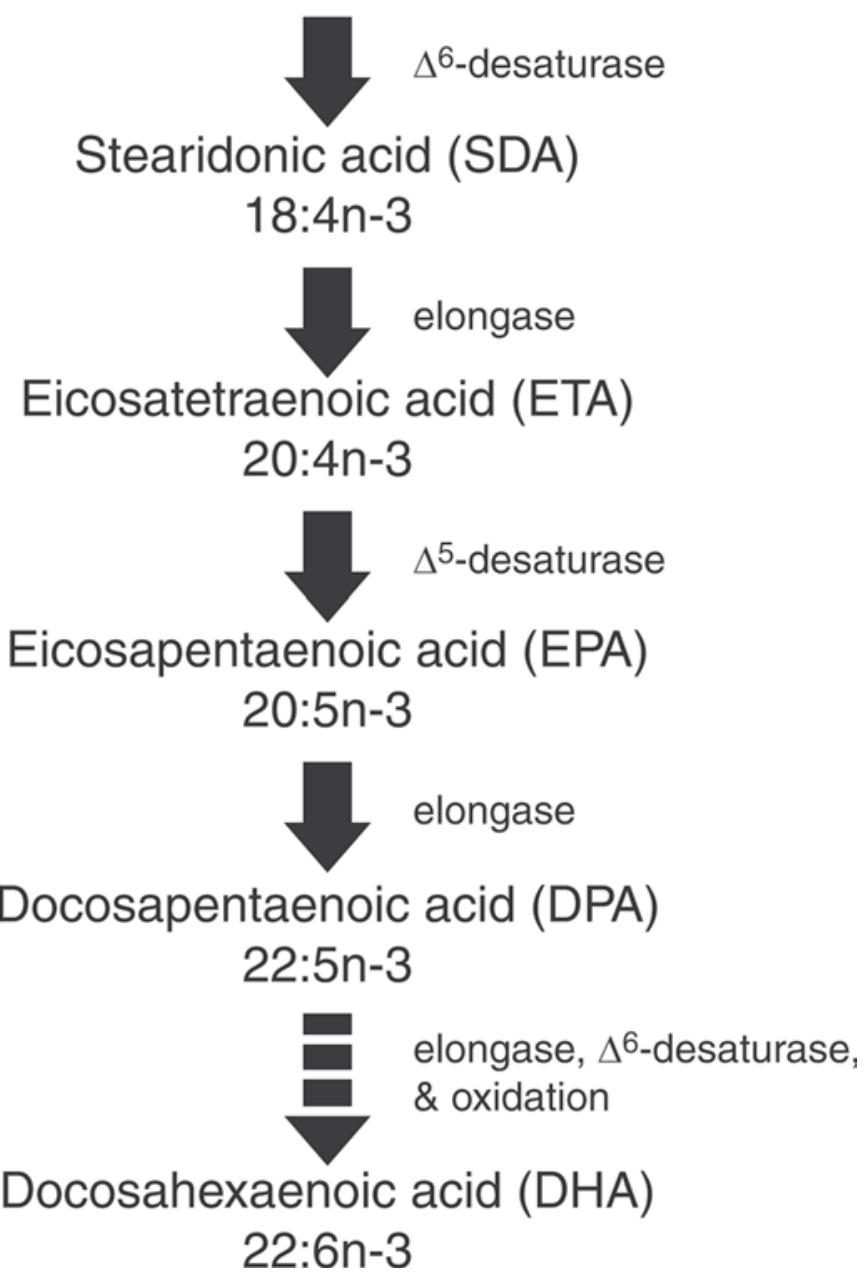

Figure 1. Biosynthesis of n-3 fatty acids.

et al., 2009; Yashodhara et al., 2009). The conversion of ALA to VLC n-3 PUFA requires $\Delta^{6}$-desaturase (Figure 1 ), an enzyme that is limiting in humans (James et al., 2003; Whelan and Rust, 2006). Stearidonic acid (SDA; 18:4n-3), a product of $\Delta^{6}$-desaturation of ALA that overcomes the rate-limiting step in n-3 metabolism (Figure 1), is of interest as a possible precursor of VLC n-3 PUFA (Ursin, 2003; Whelan, 2009). Genetic modification of oilseeds such as soybeans is an approach that can be used to increase the SDA in soybean oil (SBO; Ursin, 2003), and toxicology studies have confirmed the safety of SDA-enhanced SBO (Hammond et al., 2008). Our objectives were to examine the potential of using SDA-enhanced SBO to increase the $\mathrm{n}-3$ fatty acid content of milk fat in dairy cows and to determine the efficiency of SDA uptake from the digestive tract and its transfer to milk fat.
To address our objectives, 3 multiparous, pregnant, rumen-fistulated Holstein cows averaging 267 DIM were assigned randomly to a $3 \times 3$ Latin square design. Treatments were as follows: 1) control (no oil infusion); 2) abomasal infusion of SDA-enhanced SBO (SDA-abo); and 3) ruminal infusion of SDA-enhanced SBO (SDArum). All animal-related procedures were approved by the Cornell University Institutional Animal Care and Use Committee. Oil infusions $(210 \mathrm{~g} / \mathrm{d})$ provided $57 \mathrm{~g} / \mathrm{d}$ of stearidonic acid, and infusion periods were $7 \mathrm{~d}$ with a 7-d washout between periods. Equal amounts of oil were infused into either the rumen or abomasum at 6 -h intervals as described previously (Castañeda-Gutiérrez et al., 2007). At each infusion, cows receiving the oil treatments were given the bolus of oil followed by 120 $\mathrm{mL}$ of water to flush the line; control cows received only the water flush.

Cows were housed in individual tie stalls at Cornell's Large Animal Research and Teaching Unit and fed ad libitum a dry diet that was formulated to meet requirements (NRC, 2001) using the Cornell Net Carbohydrate and Protein System (Fox et al., 2004). The forage was a mixture of alfalfa hay and grass hay, and the TMR was 50:50 forage:concentrate (90.0\% DM, $17.6 \%$ CP, $40.6 \%$ $\mathrm{NDF}, 25.0 \% \mathrm{ADF}$, and $3.1 \%$ crude fat). Cows were milked twice a day with 2 milk samples obtained at each milking. One milk sample was analyzed for major components (fat, protein, lactose) by infrared analysis (AOAC, 2000: method 972.160; Dairy One Cooperative Inc., Ithaca, NY). The second milk sample was analyzed for fatty acids with extraction, methylation, and gas chromatographic analysis as described previously (Tyburczy et al., 2008). Fatty acids were quantified by comparison with pure methyl ester standards (NuChek Prep, Elysian, MN), and a butter oil reference standard (CRM 164; Commission of the European Communities, Community Bureau of Reference, Brussels, Belgium) was analyzed periodically to monitor column performance and correction factors for individual fatty acids. Identification of the less common n-3 milk fatty acids was confirmed using GC-MS by the laboratory of J. T. Brenna (Division of Nutritional Sciences, Cornell University, Ithaca, NY).

Statistical analyses were conducted using PROC GLM of SAS (version 5, SAS Institute, Cary, NC). One cow suffered a physical injury and had to be removed from the study just before the start of her third period (abomasal infusion) resulting in a missing cell.

The SDA-enhanced soybean oil contained 27.1\% SDA, $10.4 \%$ ALA, and $7.3 \% \gamma$-linolenic acid; relative to the typical fatty acid composition of SBO, these fatty acid increases were offset mainly by a reduction in linoleic and oleic acids (Table 1). Infusion of the SDA-enhanced SBO into the rumen or abomasum had no effect on DMI 
BERNAL-SANTOS ET AL.

Table 1. Major fatty acids (\% of total fatty acids) in the stearidonic acid-enriched soybean oil

\begin{tabular}{|c|c|c|}
\hline Fatty acid & SDA-enhanced $\mathrm{SBO}^{1}$ & Soybeans $^{2}$ \\
\hline Palmitic acid, 16:0 & 12.50 & $11.4 \pm 1.9$ \\
\hline Stearic acid, 18:0 & 4.26 & $4.1 \pm 0.6$ \\
\hline Oleic acid, 18:1 & 14.66 & $22.3 \pm 2.5$ \\
\hline Linoleic acid, 18:2n-6 & 18.42 & $53.5 \pm 3.2$ \\
\hline$\gamma$-Linolenic acid, 18:3n-6 & 7.25 & $7.0 \pm 1.9^{3}$ \\
\hline$\alpha$-Linolenic acid, $18: 3 n-3$ & 10.43 & \\
\hline Stearidonic acid, $18: 4 n-3$ & 27.10 & \\
\hline
\end{tabular}

or milk production; across treatments daily DMI and milk production averaged (least squares means $\pm \mathrm{SE}$ ) $22.9 \pm 0.5 \mathrm{~kg}$ and $32.3 \pm 0.9 \mathrm{~kg}$, respectively. Likewise, treatments did not differ in milk protein percentage and yield $(3.24 \pm 0.04 \%$ and $1.03 \pm 0.02 \mathrm{~kg} / \mathrm{d}$, respectively) or milk lactose percentage and yield (4.88 \pm $0.05 \%$ and $1.55 \pm 0.05 \mathrm{~kg} / \mathrm{d}$, respectively). In the case of milk fat, yield was unaffected by treatment $(1.36 \pm$ $0.03 \mathrm{~kg} / \mathrm{d})$, but milk fat percentage was less $(P<0.01)$ for the SDA-rum treatment $(4.04 \pm 0.04 \%)$ compared with the control $(4.30 \pm 0.04 \%)$ and SDA-abo (4.41 $\pm 0.05 \%)$ treatments. Polyunsaturated fatty acids are biohydrogenated in the rumen, which often results in the production of fatty acid intermediates that inhibit mammary synthesis of milk fat (Harvatine et al., 2009). These effects are less pronounced or negligible when the intake of PUFA is reduced or meal frequency is increased (Bauman and Griinari, 2001). In the present study the rumen infusion treatment supplied only about $52 \mathrm{~g}$ of SBO every $6 \mathrm{~h}$; thus, the minimal effects on milk fat percentage were as expected.

Examination of milk fatty acid composition revealed that many fatty acids were unchanged, but changes were observed in some fatty acids and these were as expected based on specific treatments. None of the individual saturated fatty acids differed among treatments (data not presented), and across treatments saturated fatty acids represented $61.0 \pm 2.1 \%$ (least squares means \pm $\mathrm{SE}$ ) of total milk fatty acids. Among the monounsaturated fatty acids, oleic acid was unaffected by treatment. However, consistent with rumen biohydrogenation of the infused PUFA, there were significant increases in the milk fat content of trans-18:1 isomers for the rumen infusion group (Table 2); generally these increases were small with the largest occurring for vaccenic acid (trans-11 18:1), which approached $2 \%$ of total milk fatty acids. Vaccenic acid originates as an intermediate in rumen biohydrogenation of 18-carbon PUFA and it is converted to cis-9, trans-11 18:2 (conjugated linoleic acid; CLA) by the mammary enzyme $\Delta^{9}$-desaturase (Bauman et al., 2006); consistent with this, the CLA content of milk fat was also increased for the SDA-rum treatment (Table 2).

As expected, the SDA-abo treatment resulted in increases in the fatty acid content of several PUFA in milk fat (Table 2). Of special interest were increases in fatty acids of the n-3 biosynthesis pathway (Figure 1), specifically ALA, SDA, eicosatetraenoic acid (ETA), and EPA. Milk fat content of docosapentaenoic acid (DPA) and DHA, two additional VLC n-3 PUFA (Figure 1), did not differ among treatment groups (Table 2 ). For the SDA-abo treatment, the temporal patterns of ALA, SDA, ETA, and EPA illustrated a progressive increase following the initiation of infusion, reaching a plateau by d 3 and 4 of infusion (Figure 2). Overall, the n-3 content of milk fat was $3.9 \%$ of total milk fatty acids with the SDA-abo treatment, a value more than $500 \%$ greater than that in milk fat from the control group (Table 2). When abomasal infusion was terminated, milk fat content of these fatty acids progressively decreased to preinfusion values following a mirror-image pattern of the increase. In contrast, rumen infusion had little or no effect on n-3 fatty acids, and milk fatty acid values of the SDA-rum treatment were similar to those of the control treatment (water infusion; Figure 2 and Table 2).

The transfer efficiency of SDA to milk fat represented $39.3 \%$ (range $=36.8$ to $41.9 \%$ ) of the SDA present in the abomasally infused oil. If increases in the n-3 fatty acids downstream from SDA are included (ETA + EPA; Figure 1), then the transfer efficiency for SDA increases to $47.3 \%$ (range $=45.0$ to $49.6 \%$ ). If there was substantial conversion of ALA to SDA and to downstream n-3 fatty acids, it would reduce the calculated transfer efficiency of SDA. However, this contribution would appear to be minor; Hagemeister et al. (1991) reported that abomasal infusion of linseed oil to dairy cows markedly increased the milk fat content of ALA, but the increase in the EPA content of milk fat was minimal, representing only $1.3 \%$ of that observed for ALA. Just as observed for humans and other species (James et al., 2003; Whelan and Rust, 2006), $\Delta^{6}$-de- 

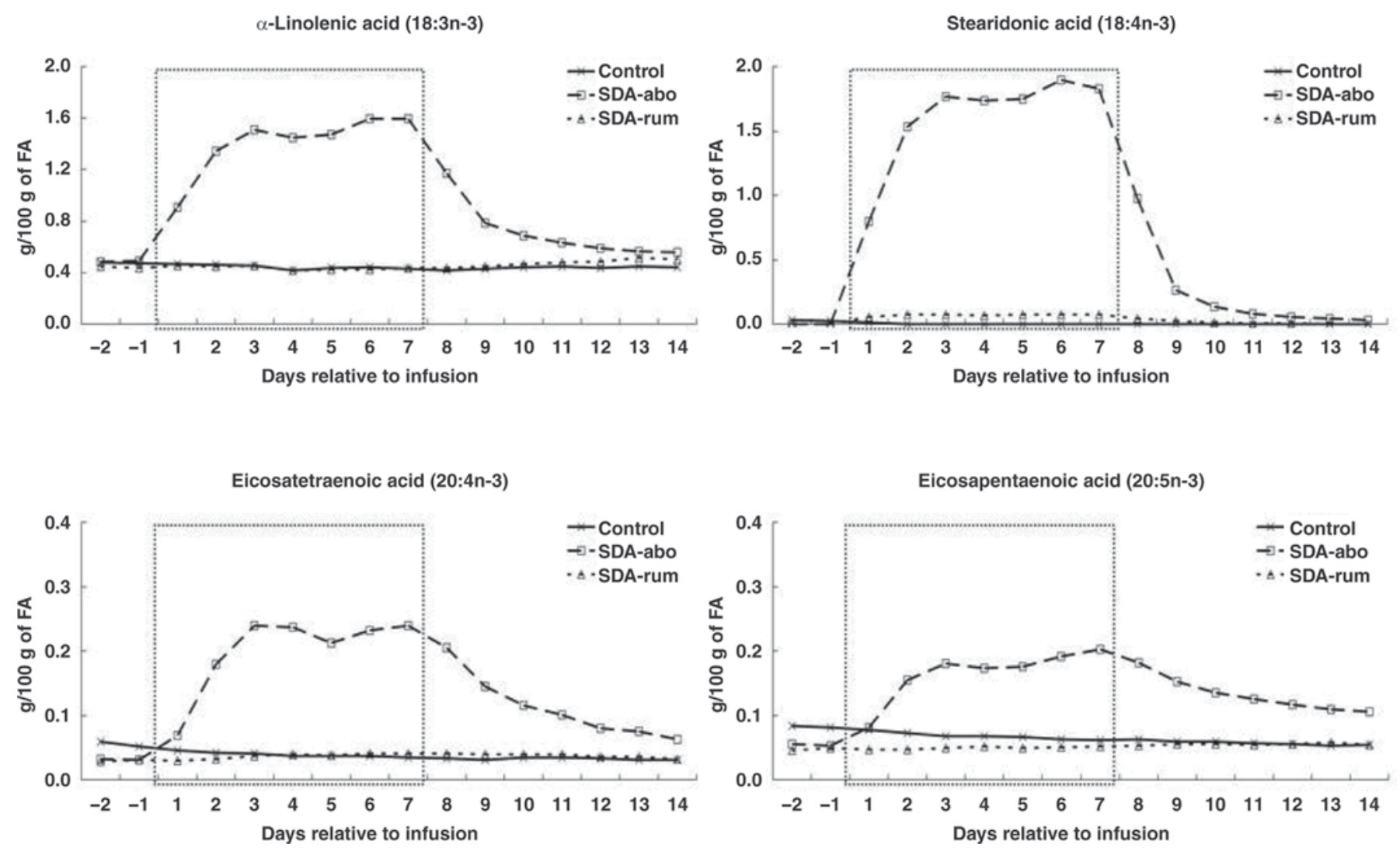

Figure 2. The temporal pattern of changes in milk fatty acids for the different treatment groups. The 3 treatments were control (water infusion), abomasal infusion of stearidonic-enhanced soybean oil (SDA-abo), and rumen infusion of stearidonic-enhanced soybean oil (SDA-rum). The 7-d infusion is shown by the boxed area, and the oil infusions (every $6 \mathrm{~h}$ ) provided $57 \mathrm{~g} / \mathrm{d}$ of stearidonic acid.

saturase appears to be rate limiting in the conversion of n-3 fatty acids in lactating dairy cows. In the current study the transfer efficiency of abomasally infused SDA plus downstream intermediates synthesized from SDA (ETA and EPA) is similar to reports of transfer efficiency for linolenic acid and greater than that typically reported for EPA and DHA. Although variation was substantial, a literature summary of infusion studies by Chilliard et al. (2000) indicated that most transfer efficiency values tended to be approximately 40 to $60 \%$ for linolenic acid, and a similar summary of EPA and DHA infusions to lactating cows indicated that milk fat transfer efficiencies were generally about 20 to $30 \%$ (Lock and Bauman, 2004). In contrast to that achieved with abomasal infusion, transfer efficiency of ruminally infused SDA to milk fat averaged only $1.7 \%$ (range = 1.3 to $2.1 \%$ ). Thus, rumen biohydrogenation of SDA must be extensive, and substantially increasing the n-3 content of milk fat would require that dietary supplements of SDA-enriched SBO be formulated to protect the SDA from rumen biohydrogenation.

Some food products are promoted as being "naturally" enriched in n-3 fatty acids. In the case of dairy products this is generally achieved by feeding rations that have a higher content of $\alpha$-linolenic acid (e.g., pasture, flaxseed, linseed oil; Lock and Bauman, 2004; Palmquist, 2009). The $\mathrm{n}-3$ fatty acids of special importance for optimal human health and the prevention of acute and chronic diseases are EPA and DHA; thus, the ability to metabolize ALA to VLC n-3 PUFA is an important nutritional consideration in humans (Whelan and Rust, 2006; Brenna et al., 2009). Unfortunately, human clinical studies have demonstrated that ALA conversion to EPA is very limited in children and adults (Arterburn et al., 2006; Brenna et al., 2009). Likewise, supplements of flaxseed to increase dietary intake of ALA result in marked increases in the ALA content of milk fat in lactating women, but changes in EPA were minimal even after $4 \mathrm{wk}$ of supplementation (Francois et al., 2003). As discussed earlier, Hagemeister et al. (1991) observed the same limited conversion of ALA to EPA in lactating cows.

Stearidonic acid is the $\Delta^{6}$-desaturase product of ALA, but unfortunately this enzyme has only limited activity in humans and, as discussed earlier, it represents a ratelimiting step in the biochemical pathway for the con- 
Table 2. Partial listing of milk fatty acids (\% of total milk fatty acids) and the effect of treatment

\begin{tabular}{|c|c|c|c|c|}
\hline Fatty acid & \multicolumn{3}{|c|}{ Treatment $^{1}$} & $P$-value ${ }^{2}$ \\
\hline Oleic acid, 18:1, cis-9 & $25.09 \pm 1.49$ & $22.10 \pm 1.97$ & $26.03 \pm 1.49$ & NS \\
\hline $18: 1$, trans $-6-8$ & $0.27^{\mathrm{b}} \pm 0.01$ & $0.20^{\mathrm{b}} \pm 0.02$ & $0.35^{\mathrm{a}} \pm 0.01$ & 0.02 \\
\hline $18: 1$, trans -9 & $0.22^{\mathrm{b}} \pm 0.01$ & $0.18^{\mathrm{b}} \pm 0.01$ & $0.32^{\mathrm{a}} \pm 0.01$ & 0.01 \\
\hline $18: 1$, trans -10 & $0.37^{\mathrm{b}} \pm 0.01$ & $0.34^{\mathrm{b}} \pm 0.02$ & $0.48^{\mathrm{a}} \pm 0.01$ & 0.02 \\
\hline$\gamma$-Linolenic acid, $18: 3 \mathrm{n}-6$ & $0.04^{\mathrm{b}} \pm 0.01$ & $0.57^{\mathrm{a}} \pm 0.01$ & $0.05^{\mathrm{b}} \pm 0.01$ & 0.0001 \\
\hline$\alpha$-Linolenic acid, 18:3n-3 & $0.44^{\mathrm{b}} \pm 0.02$ & $1.55^{\mathrm{a}} \pm 0.03$ & $0.43^{\mathrm{b}} \pm 0.02$ & 0.0001 \\
\hline Rumenic acid, cis- 9 , trans- $11 \mathrm{CLA}^{3}$ & $0.45^{\mathrm{b}} \pm 0.03$ & $0.31^{\mathrm{b}} \pm 0.05$ & $0.70^{\mathrm{a}} \pm 0.03$ & 0.01 \\
\hline Stearidonic acid, 18:4n-3 & $<0.01^{\mathrm{b}}$ & $1.86^{\mathrm{a}} \pm 0.02$ & $0.07^{\mathrm{b}} \pm 0.02$ & 0.0001 \\
\hline Arachidonic acid, 20:4n-6 & $0.17 \pm 0.01$ & $0.19 \pm 0.01$ & $0.15 \pm 0.01$ & NS \\
\hline Eicosatetraenoic acid, 20:4n-3 & $0.04^{\mathrm{b}} \pm<0.01$ & $0.23^{\mathrm{a}} \pm<0.01$ & $0.04^{\mathrm{b}} \pm<0.01$ & 0.0001 \\
\hline
\end{tabular}

${ }^{\mathrm{a}, \mathrm{b}}$ Within-row differences are indicated by different superscripts.

${ }^{1}$ Control = no oil infusion; SDA-abo = abomasal infusion of stearidonic acid (SDA)-enhanced soybean oil (SBO); SDA-rum = ruminal infusion of SDA-enhanced SBO.

${ }^{2}$ Probability of significant difference among treatments. NS $=$ nonsignificant at $P>0.1$.

${ }^{3} \mathrm{CLA}=$ conjugated linoleic acid.

version of dietary ALA to EPA (Figure 1). Stearidonic acid has been targeted as a potential intermediate for use in foods because it bypasses this enzymatic step, and human clinical comparisons with EPA supplements indicate that supplements of SDA provide EPA equivalence at moderate intakes (Ursin, 2003; Whelan, 2009). Natural sources of SDA include plants from the Boraginaceae family (e.g., seed oils from Echium and borage) and some fish oils (which contain up to 4\% SDA); however, SDA sources are limited and inadequate for wide-scale enrichment of feeds and foods (Ursin, 2003; Whelan, 2009). Introduction of the genes for $\Delta^{6}$ - and $\Delta^{15}$-desaturases into soybeans allows for the conversion of linoleic acid to ALA (via $\Delta^{15}$-desaturase) and ALA to SDA (via $\Delta^{6}$-desaturase) resulting in the production of SDA-enhanced SBO. Previous investigations with SDA-enhanced SBO have evaluated the effectiveness and safety in humans (Harris et al., 2008) and rodents (Hammond et al., 2008). Likewise, studies in humans have shown that SDA supplements resulted in elevated EPA compared with ALA supplements, but DHA was unaltered (James et al., 2003; Harris et al., 2008). We also observed that abomasal infusion of SDA-enhanced SBO resulted in increased milk fat content of SDA as well as the downstream intermediates ETA and EPA, but DHA was unaffected in lactating cows (Table 2).

Dietary intake of EPA plus DHA averages approximately $100 \mathrm{mg} / \mathrm{d}$ for the US population (Ervin et al., 2004), which compares with the recommendation of 500 $\mathrm{mg} / \mathrm{d}$ for healthy individuals and 800 to $1,000 \mathrm{mg} / \mathrm{d}$ for individuals with coronary heart disease (Lavie et al.,
2009). Our goal was to investigate whether SDA uptake from the digestive tract would result in an increase in the $\mathrm{n}-3$ fatty acid content of milk fat. The potential impact of the observed changes in milk fatty acid composition on the US diet would need to be evaluated as part of a comprehensive dietary assessment. However, assuming industry-wide adoption and effective rumen protection technology, data for US dietary intakes can be combined with results from the present study to provide an estimate. Using the US dietary intake of fat from dairy products estimated from the National Health and Nutrition Examination Survey (Ervin et al., 2004) and assuming that humans convert approximately $25 \%$ of dietary SDA to EPA (Whelan, 2009), dairy products produced from the milk of cows receiving the SDAabo treatment would add approximately $90 \mathrm{mg} / \mathrm{d}$ of VLC n-3 PUFA to the diet of an average US individual without altering fat consumption. This would represent a significant contribution toward meeting the recommendation for VLC n-3 PUFA intake.

The present study presents the first results on the uptake and transfer of SDA to milk fat in dairy cows. The SDA source was genetically modified soybeans, and our results demonstrated that abomasal infusion of SDA-enhanced SBO resulted in a 5-fold increase in the n-3 fatty acid content of milk fat, specifically increasing ALA, SDA, ETA, and EPA. Relative to meeting the human dietary requirements for n-3 fatty acids, an increase in SDA has an advantage over ALA because humans can more efficiently convert SDA to EPA. However, our results also indicate that rumen- 
protected formulations of SDA-enriched SBO would be needed to achieve increases in the n-3 fatty acid content of milk fat. Additional studies and animal numbers are required to more fully evaluate individual cow variation and develop dose-response relationships. Nevertheless, results from the present study clearly demonstrate the impressive potential to utilize SDA-enhanced soybeans to achieve increases in the n-3 fatty acid content of dairy products of benefit to human health.

\section{ACKNOWLEDGMENTS}

This study was supported in part by Cornell Agricultural Experimental Station and Smith Lever funds from the Cooperative State Research, Education, and Extension Service, U.S. Department of Agriculture, under Agreement No. NYC-127437. Any opinions, findings, conclusions, or recommendations expressed in this publication are those of the authors and do not necessarily reflect the view of the US Department of Agriculture. Funding to support the study was also provided by Monsanto Co. (St. Louis, MO). The authors gratefully acknowledge the contributions of Cornell University colleagues O. Cristobal, K. C. McRoberts, and J. Alishauskas (Department of Animal Science) in the conduct of the study and the assistance of S. Alves and J. T. Brenna (Division of Nutritional Sciences) in verifying the identity of SDA intermediates in the GC analysis.

\section{REFERENCES}

AOAC. 2000. Official Methods of Analysis. 17th ed. Assoc. Off. Anal. Chem., Arlington, VA.

Arterburn, L. M., E. Bailey Hall, and H. Oken. 2006. Distribution, interconversion, and dose response of n-3 fatty acids in humans. Am. J. Clin. Nutr. 83(Suppl.):1467S-1476S.

Bauman, D. E., and J. M. Griinari. 2001. Regulation and nutritional manipulation of milk fat: Low-fat milk syndrome. Livest. Prod. Sci. 70:15-29.

Bauman, D. E., I. Mather, R. Wall, and A. L. Lock. 2006. Major advances associated with the biosynthesis of milk. J. Dairy Sci. $89: 1235-1243$

Brenna, J. T., N. Salem Jr., A. J. Sinclair, and S. C. Cunnane. 2009. $\alpha$-Linolenic acid supplementation and conversion to n-3 long-chain polyunsaturated fatty acids in humans. Prostaglandins Leukot. Essent. Fatty Acids 80:85-91.

Castañeda-Gutiérrez, E., M. J. de Veth, A. L. Lock, D. A. Dwyer, K. D. Murphy, and D. E. Bauman. 2007. Effect of supplementation with calcium salts of fish oil on n-3 fatty acids in milk fat. J. Dairy Sci. 90:4149-4156.

Chilliard, Y., A. Ferlay, R. M. Mansbridge, and M. Doreau. 2000. Ruminant milk fat plasticity: Nutritional control of saturated, polyunsaturated, trans and conjugated fatty acids. Ann. Zootech. 49:181-205.

Ervin, R. B., J. D. Wright, C.-Y. Wang, and J. Kennedy-Stephenson. 2004. Dietary intake of fats and fatty acids for the United States population: 1999-2000. Adv. Data 348:1-6.

Fox, D. G., L. O. Tedeschi, T. P. Tylutki, J. B. Russell, M. E. Van Amburgh, L. E. Chase, A. N. Pell, and T. R. Overton. 2004.
The Cornell Net Carbohydrate and Protein System model for evaluating herd nutrition and nutrient excretion. Anim. Feed Sci. Technol. 112:29-78.

Francois, C. A., S. L. Connor, L. C. Bolewicz, and W. E. Connor. 2003. Supplementing lactating women with flaxseed oil does not increase docosahexaenoic acid in their milk. Am. J. Clin. Nutr. $77: 226-233$

Gebauer, S. K., T. L. Psota, W. S. Harris, and P. M. Kris-Etherton. 2006. n-3 Fatty acid dietary recommendations and food sources to achieve essentiality and cardiovascular benefits. Am. J. Clin. Nutr. 83(Suppl.):1526S-1535S.

Glasser, F., A. Ferlay, and Y. Chilliard. 2008. Oilseed lipid supplements and fatty acid composition of cow milk: A meta-analysis. J. Dairy Sci. 91:4687-4703.

Hagemeister, H. D., D. Precht, M. Franzen, and C. A. Barth. 1991. $\alpha$-Linolenic acid transfer into milk fat and its elongation by cows. Fat Sci. Technol. 93:387-391.

Hammond, B. G., J. K. Lemen, G. Ahmed, K. D. Miller, J. Kirkpatrick, and T. Fleeman. 2008. Safety assessment of SDA soybean oil: Results of a 28-day gavage study and a 90-day/one generation reproduction feeding study in rats. Regul. Toxicol. Pharmacol. $52: 311-323$.

Harris, W. S., S. L. Lemke, S. N. Hansen, D. A. Goldstein, M. A DiRienzo, H. Su, M. A. Nemet, M. L. Taylor, G. Ahmed, and C. George. 2008. Stearidonic acid-enhanced soybean oil increased the omega-3 index, an emerging cardiovascular risk marker. Lipids 43:805-811.

Harvatine, K. J., Y. R. Boisclair, and D. E. Bauman. 2009. Recent advances in the regulation of milk fat synthesis. Animal 3:4054 .

James, M. J., V. M. Ursin, and L. G. Cleland. 2003. Metabolism of stearidonic acid in human subjects: Comparison with the metabolism of other n-3 fatty acids. Am. J. Clin. Nutr. 77:11401145.

Jensen, R. G. 2002. Invited review: The composition of bovine milk lipids: January 1995 to December 2000. J. Dairy Sci. 85:295350

Lavie, C. J., R. V. Milani, M. R. Mehra, and H. O. Ventura. 2009. Omega-3 polyunsaturated fatty acids and cardiovascular diseases. J. Am. Coll. Cardiol. 54:585-594.

Lock, A. L., and D. E. Bauman. 2004. Modifying milk fat composition of dairy cows to enhance fatty acids beneficial to human health. Lipids 39:1197-1206.

NRC. 2001. Nutritional Requirements of Dairy Cattle. 7th rev. ed. Natl. Acad. Sci., Washington, DC

Palmquist, D. L. 2009. Omega-3 fatty acids in metabolism, health, and nutrition and for modified animal product foods. Prof. Anim. Sci. 25:207-249.

Tyburczy, C., A. L. Lock, D. A. Dwyer, F. Destaillats, Z. Mouloungui, L. Candy, and D. E. Bauman. 2008. Uptake and utilization of trans octadecenoic acids in lactating dairy cows. J. Dairy Sci. 91:3850-3861.

Ursin, V. M. 2003. Modification of plant lipids for human health: Development of functional land-based omega-3 fatty acids. J. Nutr. 133:4271-4274.

Wang, C., W. S. Harris, M. Chung, A. H. Lichtenstein, E. M. Balk, B. Kupelnick, H. S. Jordon, and J. Lau. 2006. n-3 Fatty acids from fish or fish-oil supplements, but not $\alpha$-linolenic acid, benefit cardiovascular disease outcomes in primary- and secondaryprevention studies: A systematic review. Am. J. Clin. Nutr. 84:517.

Whelan, J. 2009. Dietary stearidonic acid is a long chain (n-3) polyunsaturated fatty acid with potential health benefits. J. Nutr. 139:5-10

Whelan, J., and C. Rust. 2006. Innovative dietary sources of n-3 fatty acids. Annu. Rev. Nutr. 26:75-103.

Yashodhara, B. M., S. Umakanth, J. M. Pappachan, S. K. Bhat, R. Kamath, and B. H. Choo. 2009. Omega-3 fatty acids: A comprehensive review of their role in health and disease. Postgrad. Med. J. 85:84-90. 